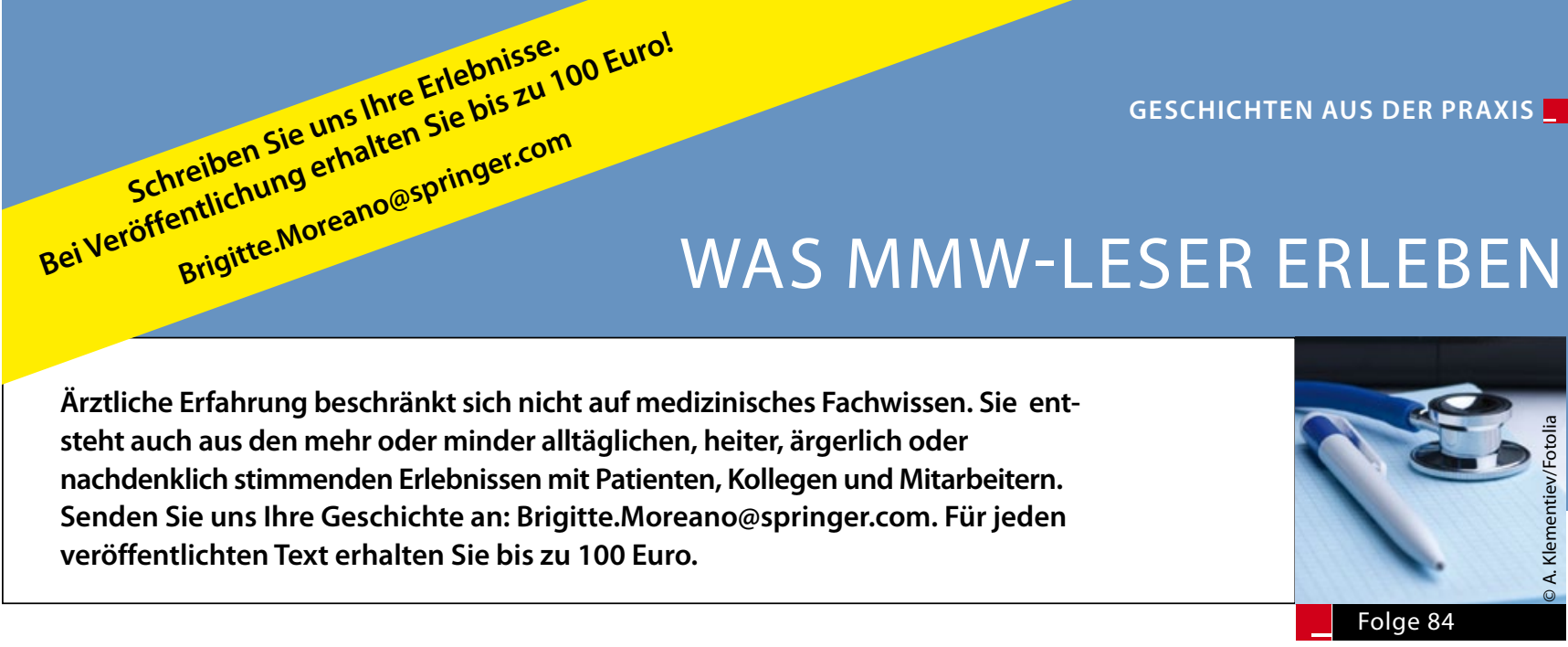

\title{
Eine wunderbare Nebenwirkung
}

- Alt werden ist nichts für Feiglinge, zumal wenn man oftmals die Hilflosigkeit des Säuglingsalters bewusst oder unbewusst erleben muss. Ich persönlich mache gegenwärtig die dritte Phase der Dentition durch, und das Einsetzen eines Dübels, im Fachjargon Implantat genannt, ist ebenso schmerzhaft und für die Umwelt belastend wie bei einem Säugling der Durchbruch der Zähne durch den Kiefer.

Man kann sich glücklich schätzen, in einer Zeit und einem Land geboren zu sein, wo ein Zahn auch zum dritten Mal wieder ersetzt werden kann, solange man das nö- tige "Kleingeld" besitzt. Nach Überwinden des einem Schwaben angeborenen Sparzwanges entschloss ich mich also zur schmerzhaften Prozedur des "Dübelns". Nach dem Eingriff wurden mir zur Prophylaxe zwei Tabletten des Antibiotikums Clindamycin 600 gereicht. Anderntags war ich überrascht, dass meine chronisch persistierenden Rückenschmerzen spurlos verschwunden waren. Neugierig geworden, ob dieses Wunder eventuell in einem Zusammenhang mit dem Clindamycin stehen könnte, entschloss ich mich, das Antibiotikum noch drei Tage länger einzunehmen, wobei zu meiner Freude keinerlei Rückenschmerzen mehr auftraten. Ein Studium der Nebenwirkungen von Clindamycin 600 brachte dann des Rätsels Lösung: Als gelegentliche Nebenwirkung wurde eine Blockade der Übertragung von Nervenreizen auf die Muskeln beschrieben. Auf diese Weise hat mir der Kieferchirurg als medizinischer Wunderheiler zwei wundervolle, schmerzfreien Wochen beschert.

Zu einer Dauerheilung hat es allerdings leider nicht gereicht.

DR. MED. UDO FUCHS, HAMBURG =

\section{Die Freuden des kassenärztlichen Notdienstes}

- An einem kalten, nebligen NovemberWochenende war ich Vertreter eines Kassenarztes im kassenärztlichen Notdienst. Am Freitagabend gegen 22:00 Uhr rief mich aus einem etwa zwölf km entfernten Ort ein Mann an, der mich wegen akuter Kreuzschmerzen bei seiner Frau anforderte. Nach einigen Verhandlungen, in denen er mich „in die Ecke trieb“, fuhr ich die zwölf km durch den Nebel. Das Ehepaar saß bei einem Bier vor dem Fernseher auf dem Sofa. Die Frau klagte über heftige Kreuzschmerzen, die seit zwei Tagen bestanden, sich aber angeblich in den letzten Stunden stark verschlimmert hätten. Bei der Untersuchung ergaben sich keine neurologischen Defizite, der Lasègue war bis etwa $40^{\circ}$ schmerzlos möglich. Ich verordnete Wärmeap- plikation und eine nicht steroidales Antirheumatikum, für das ich ein Rezept ausstellte. Der Mann bestand darauf, dass ich

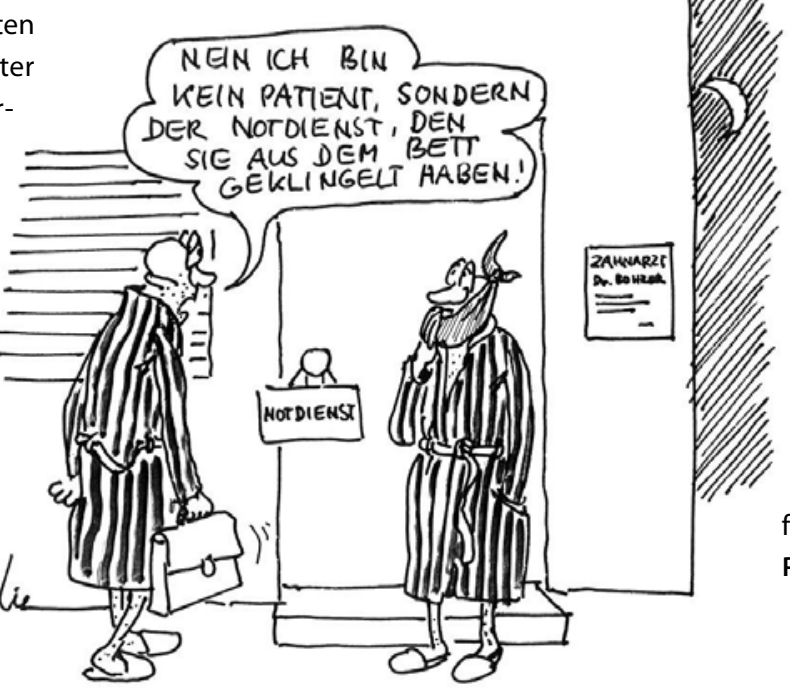

seiner Frau eine Spritze geben solle, was ich jedoch unter Berücksichtigung der relativ geringen Beschwerden und unter Hinweis auf die Risiken von i. m.Injektionen verweigerte. Die Stimmung beim Abschied hatte sich nicht gerade verbessert.

Am Sonntagabend kam ich zufällig an der diensthabenden Apotheke unserer Kleinstadt vorbei und erkundigte mich, ob für Frau XY ein Rezept für Voltaren eingelöst worden sei. Die Apothekerin machte sich die Mühe und sah sämtliche Rezepte des Wochenendes durch. Eine Frau XY fand sich darunter nicht.

PROF. DR. MED. H.-S. FüESSL, MÜNCHEN = 